\title{
Wave Run-Up on the Zeebrugge Rubble Mound Breakwater: Full-Scale Measurement Results
}

\author{
Julien De Rouck ${ }^{\dagger}$, Björn Van de Walle ${ }^{\ddagger}$, Peter Troch ${ }^{\dagger}$, Jentsje van der Meer ${ }^{\S}$, Luc Van Damme ${ }^{\dagger \dagger}$, \\ Josep R. Medina ${ }^{\ddagger \neq}$, Marc Willems ${ }^{8 \S}$, and Peter Frigaard
}

${ }^{\dagger}$ Ghent University

Department of Civil

Engineering

Technologiepark 904

B-9052 Gent, Belgium

julien.derouck@ugent.be

peter.troch@ugent.be

*Universidad Politécnica de

Valencia

Departamento Transportes/

ETSI Caminos

Camino de Vera s/n

E-46022 Valencia, Spain

jrmedina@tra.upv.es

\author{
*Katholieke Hogeschool \\ Brugge Oostende (KHBO) \\ Departement Industriële \\ Wetenschappen en \\ Technologie (IW\&T) \\ Zeedijk 101 \\ B-8400 Oostende, Belgium \\ bjorn.vandewalle@khbo.be
${ }^{88}$ Ministry of the Flemish
Community
Flanders Hydraulics
Berchemlei 115
marcl.willems@lin.
vlaanderen.be \\ B-2140 Borgerhout, Belgium
}

\$Infram

P.O. Box 81

Patroonsweg 29

NL-3892 AB Zeewolde, The

Netherlands

jentsje.vandermeer@infram.nl

\author{
${ }^{*}$ Ministry of the Flemish \\ Community \\ Coastal Division \\ Vrijhavenstraat 3 \\ B-8400 Oostende, Belgium \\ luc.vandamme@lin. \\ vlaanderen.be
}

\author{
Halborg University \\ Department of Civil \\ Engineering \\ Sohngaardsholmsvej 57 \\ DK-9000 Aalborg, Denmark \\ peter.frigaard@civil.auc.dk
}

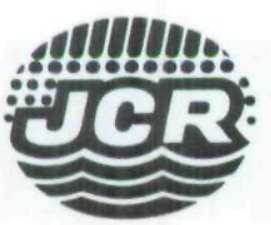

ABSTRACT

DE ROUCK, J.; VAN DE WALLE, B.; TROCH, P.; VAN DER MEER, J.; VAN DAMME, L.; MEDINA, J.R.; WILLEMS, M., and FRIGAARD, P., 2007. Wave Run-Up on the Zeebrugge Rubble Mound Breakwater: Full-Scale Measurement Results. Journal of Coastal Research, 23(3), 577-583. West Palm Beach (Florida), ISSN 0749-0208.

Full-scale wave run-up measurements have been carried out on the Zeebrugge rubble mound breakwater in the frame of the EU-funded OPTICREST project. Wave run-up has been measured by a run-up gauge and by a so-called spiderweb system. The dimensionless wave run-up value $R u_{2 q} / H_{m 0}$ measured in Zeebrugge equals 1.77 for Iribarren number $\xi_{\text {om }}=3.63$. An (apparent) influence of the water level on wave run-up has been observed. The porosity of the armor layer has a significant influence on wave run-up and may explain the dependency of wave run-up on the water level observed in Zeebrugge. Full-scale measurement results have been compared to literature data. The full-scale wave run-up data are in good agreement with the existing results of wave run-up tests with rip-rap slopes but are clearly higher than other wave run-up data resulting from tests with rubble mound breakwaters.

ADDITIONAL INDEX WORDS: Prototype, grooved cubes, gauge.

\section{INTRODUCTION}

Breakwaters are designed either by physical model tests or by numerical modeling. Design sea state conditions are generated, and structures are designed to withstand these conditions. Both physical and numerical models need verification and validation by full-scale data.

Breakwaters are designed for allowable wave overtopping conditions (GoDA, 1985). Compared to wave overtopping, wave run-up is of secondary importance for design. Because design conditions are not likely to occur and are estimated to occur only once in 1000 or 10,000 years, validation on wave overtopping is hard to perform. Models have to be calibrated for more "moderate" storm conditions. For these conditions, wave run-up is the appropriate parameter to investigate.

Although monitoring of the structure is important to have an idea about the actual behavior of the construction under

DOI:10.2112/04-0157.1 received 23 January 2004; accepted in revision 3 January 2005. less severe sea state conditions than the design sea state conditions, full-scale measurements of wave-structure interaction are very scarce. This is not only because of the expensive character of the measuring campaigns and the dependency of the feasibility on weather conditions but also because of the harsh marine environment in which sensitive instrumentation needs to be installed and accurate measurements have to be performed. Full-scale measurements are indispensable to validate small-scale model test results and results of numerical models. However, full-scale measurements yield data only within a limited range of sea state parameters and structural parameters.

Full-scale measurements on the Zeebrugge rubble mound breakwater (Belgium) have been performed within the European MAST III OPTICREST project (The Optimization of Crest Level Design of Sloping Coastal Structures Through Prototype Monitoring and Modeling, 1998-2001, contract number MAS3-CT97-0116) (DE Rouck et al., 2000, 2001). The four main objectives were (1) to improve existing wave 


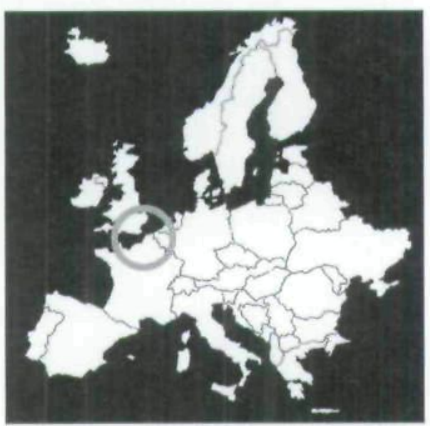

(a)

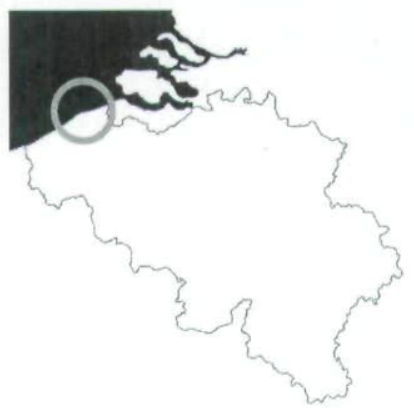

(b)

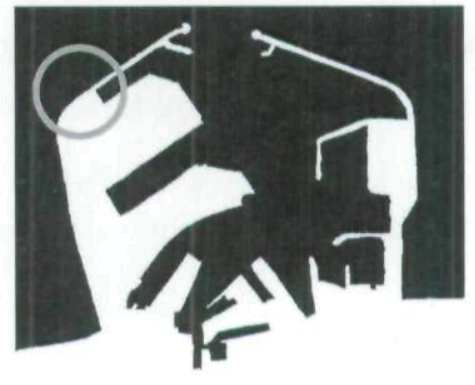

(c)

Figure 1. Location of the measuring site: (a) Europe, (b) Belgium, (c) outer harbor of Zeebrugge.

run-up monitoring devices, (2) to verify physical scale model data with prototype wave run-up data, (3) to provide improved design rules for the crest level of sloping coastal structures, and (4) to calibrate numerical models with prototype and small-scale wave run-up data.

In Zeeburgge (Belgium), it was possible to measure wave run-up during less severe sea state conditions than the design sea state conditions. Only during a limited number of storms did waves overtop the structure.

This paper describes the Zeebrugge measurement site, discusses the full-scale measurement results, and compares these to literature data.

\section{FULL-SCALE MEASUREMENTS ON THE ZEEBRUGGE BREAKWATER}

\section{General}

Full-scale measurements have been carried out on the northern part of the western breakwater of the outer harbor of Zeebrugge (Belgium) (Figure 1). The design conditions of the breakwater include significant wave height $H_{s}=6.20 \mathrm{~m}$, maximum peak wave period $T_{p}=9 \mathrm{~s}$, and still water level $\mathrm{SWL}=Z+6.75(Z+0.00=\mathrm{TAW}-0.11)$. The armor layer consists of 25-ton flattened grooved cubes. The breakwater core consists of quarry run 2-300 kg, and 1- to 3-ton rock has been used to construct the filter layer. A tide cycle lasts for $12 \mathrm{~h} 26 \mathrm{~min}$, and the SWL varies between $Z+4.62$ (MHWS) and $Z+0.32$ (MLWS). The tidal range varies between 4.30 $\mathrm{m}$ at spring tide and $3.40 \mathrm{~m}$ at neap tide.

A measuring jetty has been built on the breakwater (Figure 2) (Troch et al., 1998). The jetty measures $60 \mathrm{~m}$ long and is supported by two concrete columns at the landward side and by a steel tube pile (pile diameter $\phi=1.80 \mathrm{~m}$ ) at the seaward side. Two wave-rider buoys (WR1 and WR2), located at a distance of 150 and $215 \mathrm{~m}$ from the breakwater's axis, provide wave data. The SWL at the toe of the breakwater has been measured by a pressure sensor and by an infrared meter. Figure 3 shows the two different measuring devices used for

\section{Measurement Jetty}

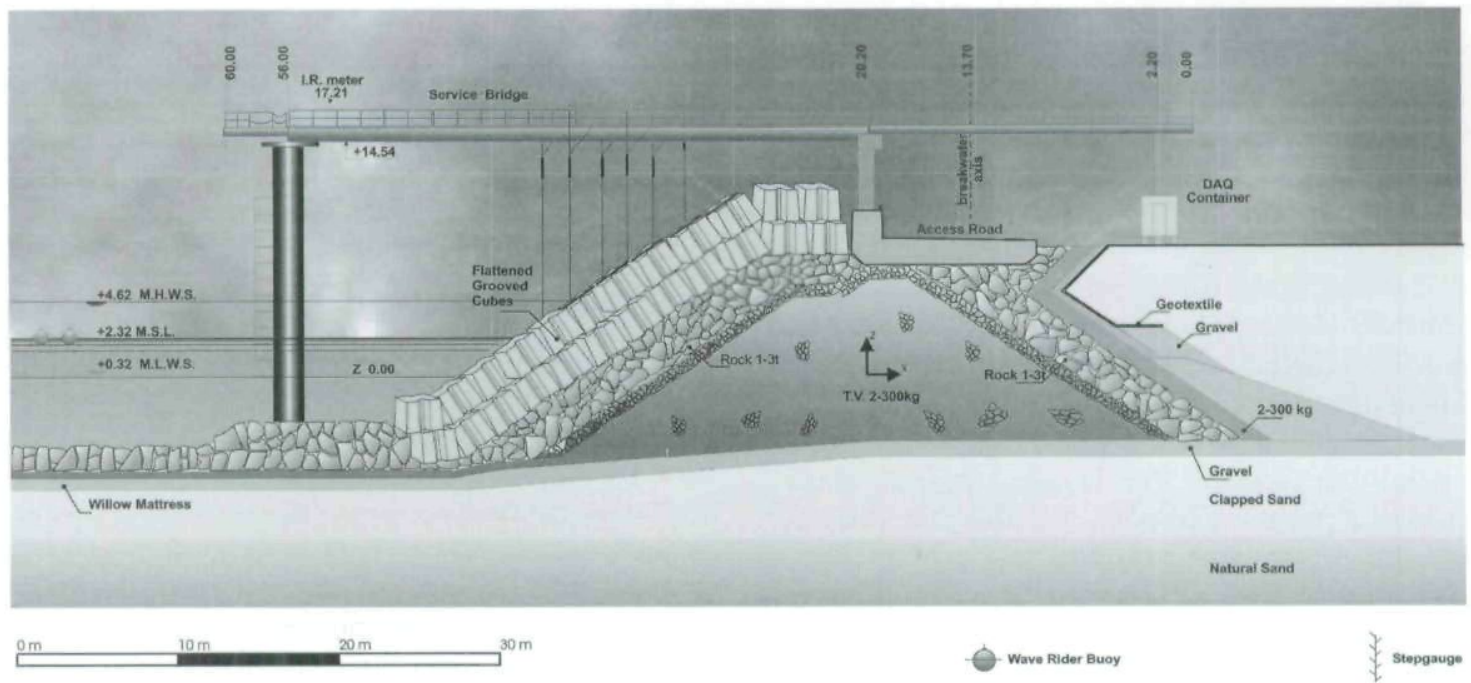

Figure 2. Cross section of the Zeebrugge breakwater with the measuring jetty. 


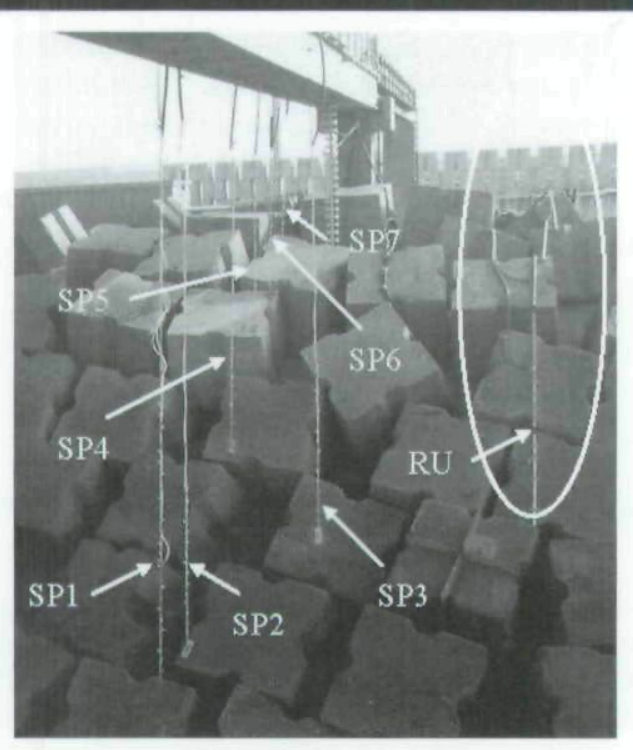

Figure 3. Two different measuring devices have been used to measure wave run-up at full scale: a so-called "spiderweb system" (SP; left and middle of picture) and a five-part run-up gauge (RU; right of the picture).

wave run-up measurements: a so-called "spiderweb system" (SP) and a run-up gauge (RU) (see VAN DE WALLE, 2003). The SP is a set of seven step gauges mounted vertically between the armour units and the jetty bridge. Each step gauge measures the water surface elevations on the breakwater slope. By means of linear extrapolation of the water level data from each of the step gauges on to the slope surface, wave run-up and wave run-down levels have been estimated. The run-up gauge (RU) consists of five individual parts and is mounted on top of the armor units. A wind gauge installed on the measuring jetty measures the wind speed.

\section{Data Analysis}

Wave run-up $R u(\mathrm{~m})$ is defined as the vertical distance between the still water level (SWL) and the level to which the leading edge of the water tongue running up the seaward slope of the breakwater extends. Wave run-up is usually characterised by $R u_{2 \%}$, i.e., the wave run-up level with a $2 \%$ exceedance probability. $R u_{x \%}$ is the run-up level that is exceeded by $x \%$ of the run-up events. The number of run-up events is defined as the number of waves within the analyzed time series. During all selected storm events, wave run-up has been measured by the SP. During the first four storms (1995 and 1998), the RU was not installed yet. Because of the absence of the upper two parts of the five-part run-up gauge, the highest wave run-up levels were not measured during three February 1999 storm events. However, in these particular cases, the $R u_{2 \%}$ levels have been estimated theoretically starting from wave run-up measurements of the installed three parts of the run-up gauge and by calculating the socalled "Rayleigh equivalent" wave run-up values. During all other storms (from November 1999 on), the RU was fully operational and well functioning. Time series with a duration of two hours at high tide (from $t_{\mathrm{HW}}-1$ to $t_{\mathrm{HW}}+1$ ) have been
Table 1. Full-scale wave run-up measurement results (SP [13 storms] and $R U$ [9 storms], from $t_{H W}-1$ to $t_{H W}+1,2-h$ time series).

\begin{tabular}{|c|c|c|}
\hline & SP & RU \\
\hline $\mathrm{Ru}_{\max } / \mathrm{H}_{\mathrm{m} 0}\left(\cong \mathrm{Ru}_{01 x} / \mathrm{H}_{\mathrm{m} 0}\right)[-]$ & 2.26 & 2.35 \\
\hline $\mathrm{Ru}_{1 \mathfrak{s}} / \mathrm{H}_{\mathrm{m} 0}[-]$ & 1.87 & 1.95 \\
\hline $\mathrm{Ru}_{2 \mathrm{se}} / \mathrm{H}_{\mathrm{m0}}[-]$ & 1.73 & 1.77 \\
\hline $\mathrm{Ru}_{5 \%} / \mathrm{H}_{\mathrm{m} 0}[-]$ & 1.50 & 1.56 \\
\hline $\mathrm{Ru}_{10 \%} / \mathrm{H}_{\mathrm{m} 0}[-]$ & 1.32 & 1.35 \\
\hline $\mathrm{Ru}_{\S} / \mathrm{H}_{\mathrm{m} 0}\left(\cong \mathrm{Ru}_{13539} / \mathrm{H}_{\mathrm{m0}}\right)[-]$ & 1.23 & 1.25 \\
\hline $\mathrm{Ru}_{25 \%} / \mathrm{H}_{\mathrm{m} 0}[-]$ & 1.02 & 0.98 \\
\hline $\mathrm{Ru}_{50} / \mathrm{H}_{\mathrm{m} 0}[-]$ & 0.72 & 0.69 \\
\hline
\end{tabular}

analyzed. Thus, approximately 1000 waves have been considered. To determine the $R u_{x \%}$ value, all wave run-up events, detected by a zero-up crossing method, have been put in descending order. The Bayesian estimator of the exceedance probability of the $p$ th wave run-up height in a series of $\mathrm{Nr}$ wave run-up heights is $p /(N r+1)$ (RICE, 1988). If necessary, an interpolation method has been used to determine $R u_{2 \%}$.

\section{Results}

Thirteen storm events have been selected out of all observed heavy weather conditions measured during the period from 1995 to 2000 along the Belgian coast. The wave climate during these storm events was characterized by an almost constant SWL (during a period of $2 \mathrm{~h}$ at high tide), a significant wave height $H_{m 0}$ varying between $2.40 \mathrm{~m}$ and $3.13 \mathrm{~m}$, a mean wave period $T_{01}$ of $6.2 \mathrm{~s}$, a peak wave period $T_{p}$ of 7.9 $\mathrm{s}$, a wind force of at least 6 Beaufort (wind speed $>11 \mathrm{~m} / \mathrm{s}$ ), and a wind blowing direction (NW) almost perpendicular to the breakwater axis.

An average $R u_{2 \sigma} / H_{m 0}$ value of 1.77 (coefficient of variation $\delta=0.0060$ ) for an average Iribarren number $\xi_{\text {om }}=3.63$ is obtained when the RU data (9 storms) are processed. The analysis of the SP data (13 storms) yields an average $R u_{2 \%}$ $H_{m 0}$ value of 1.73 (coefficient of variation $\delta=0.0046$ ) for an average Iribarren number $\xi_{o m}=3.64$.

Within one and the same storm event, the two measuring devices measure different wave run-up levels. The maximal measured difference is $13.8 \%$. This difference results from the irregularity of the armor layer and the fact that the two devices are placed in different cross sections. The distance between the two is approximately three times the nominal diameter $D_{n}$ of the armor units. However, on average, the two measuring systems measure almost the same $R u_{2 q} / H_{m 0}$ value. $R u_{x^{r} \%} / H_{m 0}$ for other values of $x$ are given in Table 1 . Because the run-up gauge measures the wave run-up level in a direct way without intervention of a computing algorithm, as is the case for the "spiderweb system," $R u_{2 \%} / H_{m 0}=1.77$ is the final wave run-up value obtained from full-scale measurements.

Wave run-down could be measured only by the first (most seaward) step gauge of the spiderweb system at high water because the level of the lowest electrode of the most seaward step gauge is $Z+2.75$, and the level of the lowest electrode of the run-up gauge (RU) is $Z+6.12$ (MHWS $=Z+4.62$ ). Table 2 gives the average $R d_{2 \%} / H_{m 0}$ values for the 13 analyzed storm events. During a period of time of $2 \mathrm{~h}$ at high 
Table 2. Full-scale wave run-down measurement results (SP [13 storms], from $t_{H W}-1$ to $t_{H W}+1,2-h$ time series).

\begin{tabular}{ll}
\hline \hline $\mathrm{Rd}_{\mathrm{max}} / \mathrm{H}_{\mathrm{m0}}\left(\cong \mathrm{Rd}_{01 \%} / \mathrm{H}_{\mathrm{m} 0}\right)[-]$ & -0.94 \\
$\mathrm{Rd}_{1 \%} / \mathrm{H}_{\mathrm{m0}}[-]$ & -0.89 \\
$\mathrm{Rd}_{5 \%} / \mathrm{H}_{\mathrm{m0}}[-]$ & -0.87 \\
$\mathrm{Rd}_{5 \%} / \mathrm{H}_{\mathrm{m0}}[-]$ & -0.83 \\
$\mathrm{Rd}_{10 \%} / \mathrm{H}_{\mathrm{m0}}[-]$ & -0.78 \\
$\mathrm{Rd}_{2} / \mathrm{H}_{\mathrm{m} 0}\left(\cong \mathrm{Rd}_{135 \%} / \mathrm{H}_{\mathrm{m0}}\right)[-]$ & -0.76 \\
$\mathrm{Rd}_{25 \%} / \mathrm{H}_{\mathrm{m0}}[-]$ & -0.69 \\
$\mathrm{Rd}_{50} / \mathrm{H}_{\mathrm{m} 0}[-]$ & -0.53 \\
\hline
\end{tabular}

tide, the average $R d_{2 \%} / H_{m 0}$ value equals -0.87 for $\xi_{o m}=3.64$ (variation coefficient $\delta=0.0046$ ).

Each storm event has been subjected to a data analysis of 12 subsequent time series of $30 \mathrm{~min}$, thus covering half a tide cycle lasting approximately $2 \mathrm{~h}$. The average of RU data analysis results of nine storm events have been plotted in Figure 4. Different values of the exceedance probability $x=1,2,5$, $10,25,50$ for dimensionless wave run-up $R u_{x \%} / H_{m 0}$ as well as the maximum and the significant wave run-up have been considered. With 30-min time series used in the analysis of the data collected by the run-up gauge during a period of 2 $\mathrm{h}$ at high tide (from $t_{\mathrm{HW}}-1$ to $t_{\mathrm{HW}}+1$ ), $R u_{2 \%} / H_{m 0}$ equals 1.80. This value is the average of the four $R u_{2 \%} / H_{m 0}$ values obtained within $\left[t_{\mathrm{HW}}-1, t_{\mathrm{HW}}+1\right]$ and is slightly higher than the result of the analysis of the entire 2 -h period as one time series; i.e., $\left(R u_{2 \%} / H_{m 0}\right)_{\mathrm{RU}}=1.77$. Three interesting observations are made from Figure 4. First, dimensionless wave runup values decrease during rising tide, have their minimum value at high water, and increase during receding tide. Second, the lower the exceedance probability $x$, the more the dimensionless wave run-up values decrease and increase. And third, dimensionless wave run-up values are slightly higher during rising tide than during receding tide. The tidal currents and/or the asymmetric tide are suspected to cause the asymmetry seen in Figure 4.

The change in $R u_{2 \%} / H_{m 0}$ value is partly explained by the changing wave steepness. The other part of the explanation is found in Figure 5, which shows the significant wave height $H_{m 0}$, the mean wave period $T_{01}$, and the absolute and relative wave run-up $R u_{2 \%}$ and $R u_{2 \%} / \mathrm{H}_{m 0}$ during a 6-h period of a 1999 storm. Not only are relative wave run-up values $R u_{2 \sigma_{0}} H_{m 0}$ smaller for higher water levels, but absolute wave run-up values $R u_{2 \%}$ also show the same course. The increase in wave run-up values for lowering water levels is explained by the fact that the breakwater was built in the early 1980s. Meanwhile, the armor units have settled. The porosity of the armor layer at lower levels became less. This decreased porosity causes higher wave run-up.

\section{COMPARISON OF FULLSCALE MEASUREMENT RESULTS WITH LITERATURE}

Full-scale wave run-up measurement results have been compared to formulae found by literature research.

The formula of LOSADA and GIMÉnEZ-CurTo (1981) is given by the equation

$$
\frac{R u}{H}=A[1-\exp (B \xi)]
$$

Though equation (1) originates from tests with regular waves, the equation has been used to describe irregular wave run-up. KINGSTON and MuRPHY (1996) reported $A=1.76$ and $B=-0.28$ for small-scale model tests on a model of the Zeebrugge rubble mound breakwater. Because KIngsToN and Murphy (1996) used $T_{02}$ instead of $T_{01}$ to describe wave run-up, equation (1) had to be rescaled to compare to the fullscale measurement results using $H_{m 0}, T_{01}$, and $\tan \alpha=1 / 1.3$. For the sea state in front of the Zeebrugge breakwater, the following relationship between the wave periods has been used: $T_{o 2} / T_{01}=0.93$ (DE RoucK et al., 1996). This value has been confirmed by full-scale measurements carried out in the framework of the OPTICREST project: $T_{02} / T_{01}=0.95$ (VAN DE WALle, 2003).

The formulae of VAN DER MEER and STAM read

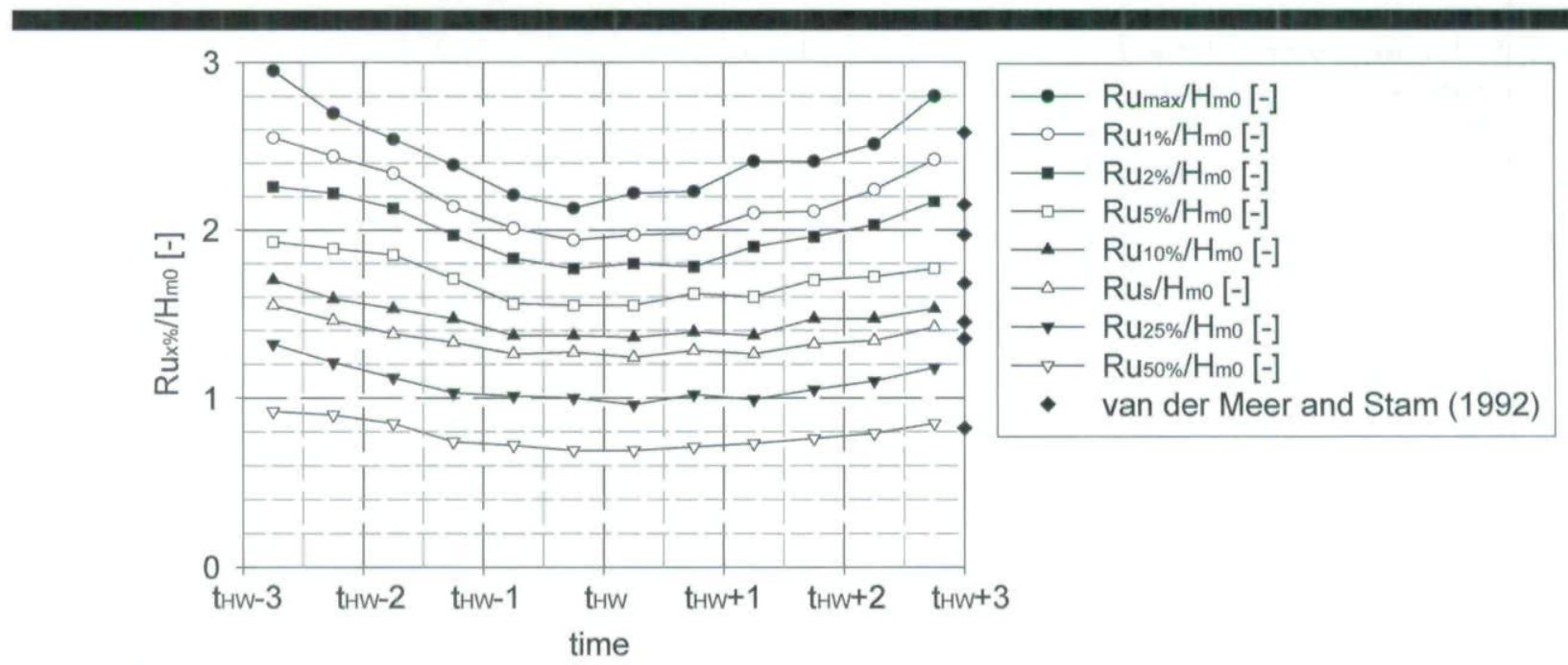

Figure 4. Dimensionless full-scale wave run-up $R u_{x^{n} \mathrm{q}} / H_{m 0}$ vs. time, 


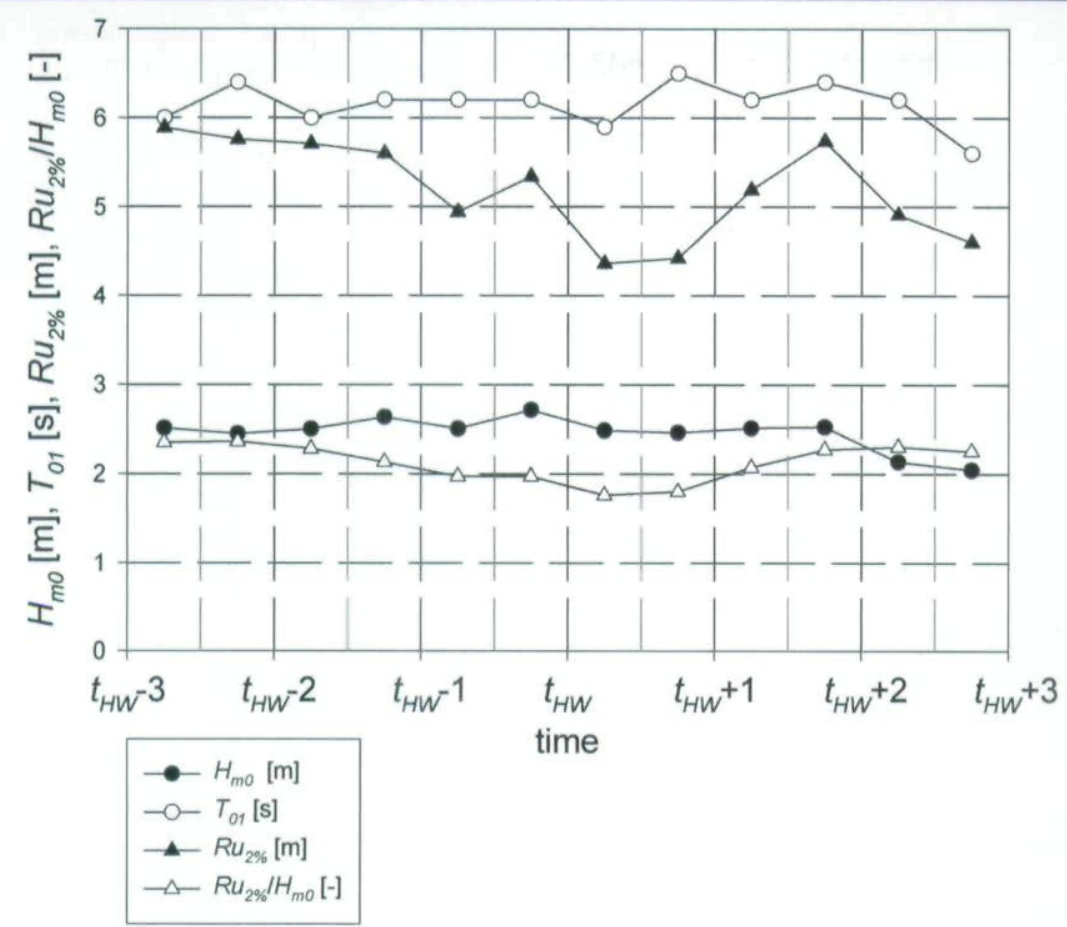

Figure 5. Significant wave height $H_{m 0}$, mean wave period $T_{01}$, wave run-up $R u_{2 \%}$, and dimensionless wave run-up $R u_{2 s} / H_{m 0}$ versus time for on particular storm event.

$$
\begin{array}{ll}
\frac{R u_{x \%}}{H_{s}}=a \xi_{o m} & \text { for } \xi_{o m} \leq 1.5 \\
\frac{R u_{x \%}}{H_{s}}=b \xi_{o m}^{c} & \text { for } \xi_{o m}>1.5
\end{array}
$$

In case of a permeable slope, equations (2) and (3) are supplemented with

$$
\frac{R u_{x}}{H_{s}}=d
$$

which is valid for relatively deep water in front of the structure where the wave height distribution is close to the Rayleigh distribution and for rock armored slopes attacked by long-crested head-on waves. This formula has been obtained by tests on rip-rap slopes with rock dimensions that are much smaller than the wave height. In the tests, $D_{n 50}=0.036 \mathrm{~m}$ and the ratio $D_{n 50} / H_{s}$ varied between 0.14 and 0.76 . In Zeebrugge, wave heights are Rayleigh distributed, but the dimensions of the armor units are of the same magnitude as the significant wave height.

Equation (1) with the values of KINGSTON and MURPHY (1996) for $A$ and $B$ and equations (2) to (4) have been plotted together with the full-scale measurement results at high tide (2-h time series data collected by both the run-up gauge and the spiderweb system within the period $\left.\left[t_{\mathrm{HW}}-1, t_{\mathrm{HW}}+1\right]\right)$ in Figure 6. The individual test results of VAN DER MEER and STAM (1992) have also been indicated by a crosshair.

The most innovative finding of this study is that wave runup on a rubble mound breakwater is much higher than ex- pected from published literature. For the full-scale value $\xi_{\text {om }}$ $=3.63$, equation (1) yields $R u_{2 \%} / H_{m 0}=1.12$ for the values of $A$ and $B$ found by KIngston and Murphy (1996). This value is much smaller than the full-scale value. KINGSTON and MuRPHY (1996) performed tests on a scale model of the Zeebrugge rubble mound breakwater and measured wave runup by a traditional wire gauge. The wave run-up-measuring technique might explain the low run-up values. During the period of $2 \mathrm{~h}$ at high tide (from $t_{\mathrm{HW}}-1$ to $t_{\mathrm{HW}}+1$ ), equation (4) yields slightly higher values than the full-scale values. The general trend given by VAN DER MEer and STAM (1992) by equation (4) is situated in the upper part of the cloud of their test results. However, the results of the full-scale measurements are found among the results of the VAN DER MEER and SтAм (1992) investigation, at the lower side.

Equations (2) to (4) have also been compared to the fullscale measurement results at the Zeebrugge site for other values of $x$. Thirty-minute time series have been used for this. From Figure 4 (the values of $R u_{\max } / H_{m 0}, R u_{1 \%} / H_{m 0}, R u_{2 \%} / H_{m 0}$, $R u_{5 \%} / H_{m 0}, R u_{10 \%} / H_{m 0}, R u_{s} / H_{m 0}$, and $R u_{50 \%} / H_{m 0}$ of VAN DER MEer and StAm [1992] are indicated by the special symbol at the right side vertical axis) it is seen that equations (2) to (4) fit the full-scale measurements remarkably very well during the time interval $\left[t_{\mathrm{HW}}-2, t_{\mathrm{HW}}-1\right]$ and $\left[t_{\mathrm{HW}}+1.5\right.$, $\left.t_{\mathrm{HW}}+2.5\right]$. During all other time intervals, full-scale measurements indicate lower dimensionless wave run-up values. However, the higher the exceedance probability $x$, the better the agreement between the formula of VAN DER MEER and STAM (1992) and the measurement results. 


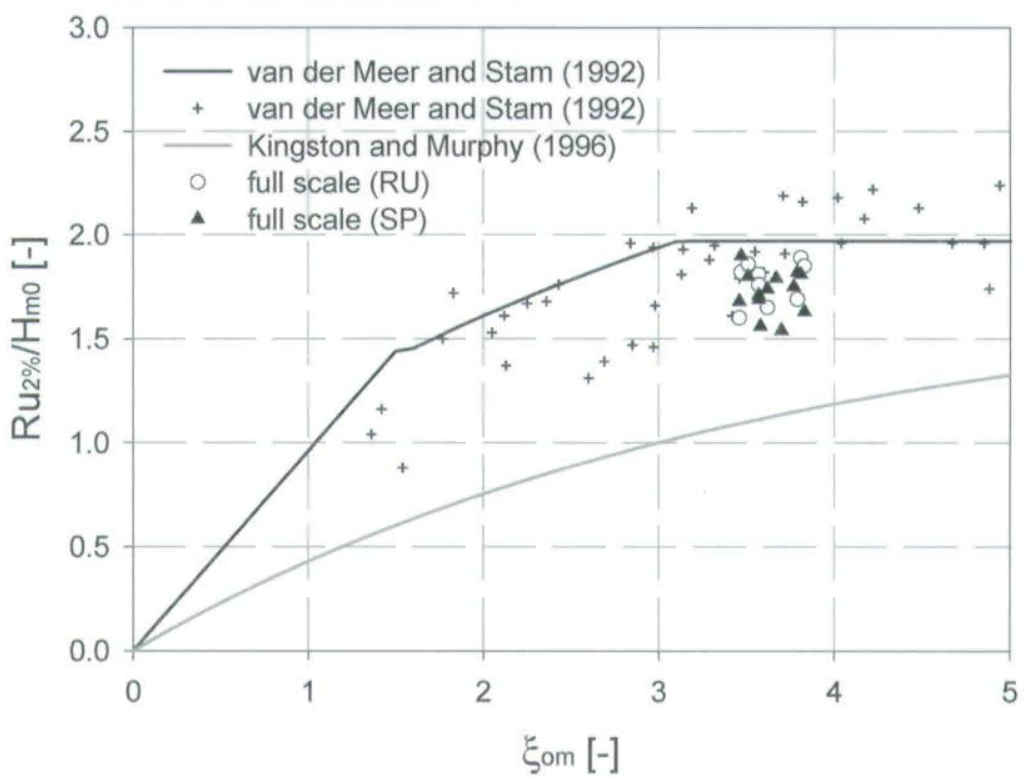

Figure 6. Comparison between dimensionless wave run-up values from full-scale measurements (from $t_{\mathrm{HW}}-1$ to $t_{\mathrm{HW}}+1$, SP [13 storms] and RU [9 storms], 2-h time series) and from literature.

Ahrens and Heimbaugh (1988) found

$$
\frac{R u_{\max }}{H_{m 0}}=\frac{a \xi}{1+b \xi}
$$

Using the surf similarity parameter $\xi_{o p}$, calculated using $T_{p}$ instead of $T_{01}$, the run-up coefficients $a$ and $b$ equal, respectively, 1.022 and 0.247 . Figure 7 shows the comparison of equation (5) to the maximum measured wave run-up on site. The individual test results of AHRENS and HeImbaugh (1988) are also depicted in Figure 7. A good agreement is seen; nonetheless, equation (5) is also based on tests with

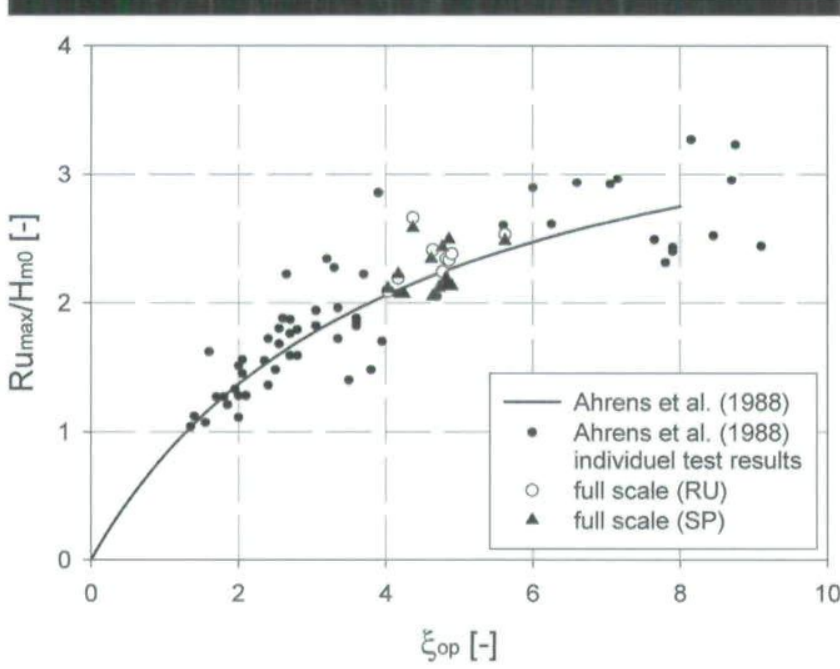

Figure 7. Comparison of full-scale wave run-up data $\left(R u_{\max } / H_{m 0}\right)$ to equation (5) ([ $\left.t_{\mathrm{HW}}-1, t_{\mathrm{HW}}+1\right], \mathrm{RU}[9 \mathrm{storms}]$ and SP [13 storms], 2-h time series). irregular waves on rip-rap-protected slopes. It has to be mentioned that the determination of $R u_{\max }$ for full-scale measurements is less accurate than the determination of $R u_{x \%}$ with $x \geq 1$.

It is concluded that wave run-up results on a rubble mound breakwater armored with grooved cubes are found among the wave run-up results on rip-rap slopes as investigated by VAN Der Meer and Stam (1992) and Ahrens and Heimbaugh (1988). Equations (2) to (4) yield a small overestimation of $R u_{2 \%} / H_{m 0}$, and equation (5) yields a very small underestimation of $R u_{\max } / H_{m 0}$.

\section{SUMMARY AND CONCLUSIONS}

Wave run-up has been measured at full scale on the Zeebrugge rubble mound breakwater by means of two measuring devices: a so-called "spiderweb system" and a wave run-up gauge. The average full-scale dimensionless wave run-up value exceeded by $2 \%$ of the waves, $R u_{2 \%} / H_{m 0}$, equals 1.77 . This value is valid for $\xi_{\text {om }}=3.6, \mathrm{SWL}=\mathrm{Z}+5.09$ and for $H_{m 0} \cong$ $D_{n 50}$ and increases when the water level is lowering. This increase may be related to the fact that the armor layer porosity at lower levels of the breakwater slope is less than the porosity at higher levels of the breakwater slope. The average full-scale dimensionless wave run-down value underspent by $2 \%$ of the waves $R d_{2 \%} / H_{m 0}$ equals -0.87 and is in agreement with observations in small-scale models. Full-scale measurement results have been compared to literature data. The fullscale wave run-up data are in good agreement with the existing results of wave run-up tests with rip-rap slopes but are clearly higher than other wave run-up data resulting from tests with rubble mound breakwaters. 


\section{ACKNOWLEDGMENTS}

The results presented in this paper are the outcome of the European Community-funded MAST III OPTICREST project (contract no. MAS3-CT97-0116). The financial support of the European Community and the Ministry of the Flemish Community is very much acknowledged. The project website is http://awww.ugent.be/opticrest.

\section{REFERENCES}

AHRENS, J.P. and HeImbaugh, M.S., 1988. Irregular wave run-up on riprap revetments, Journal of Waterway, Port, Coastal, and Ocean Engineering, 114(4), 524-530.

De Rouck, J. and Troch, P., 1996. Detailed Scientific Report of MAST 2 project: Full Scale Dynamic Load Monitoring of Rubble Mound Breakwaters, Ghent University, Gent, Belgium.

De RoucK, J.; Boone, C., and VAN DE WALle, B., 2001. OPTICREST-The optimisation of crest level design of sloping coastal structures through prototype monitoring and modelling (MAS3CT97-0116), Final report, Detailed scientific report, MAS03/1031, http://awww.ugent.be/opticrest (accessed February 16, 2002).

De Rouck, J.; Troch, P.; van DE WALle, B.; VAN DAMME, L., and BAL, J., 2000. The optimisation of crest level design of sloping coastal structures through prototype monitoring and modelling, EurOCEAN 2000 Conference, August-September 2000, Hamburg (Germany).

GoDA, Y., 1985. Random Seas and Design of Maritime Structures. Tokyo: University of Tokyo.

KInGSTON, K., and MurPHY, J., 1996. Thematic Report: Wave Runup/Run-down. Cork, Ireland: MAST II Report, 1996.

LosAdA, M.A., and GIMÉNEz-CuRTo, L.A., 1981. Flow characteristics on rough, permeable slopes under wave action, Coastal Engineering, 1981(4), 187-206.

Rice, J.A., 1988. Mathematical Statistics and Data Analysis. Belmont, California: Wadsworth.

Troch, P.; De Rouck, J., and van Damme, L., 1998. Instrumentation and prototype measurements at the Zeebrugge rubble mound breakwater, Coastal Engineering, 35, 141-166.

VAN DER MEER, J.W., and STAM, C.J., 1992. Wave run-up on smooth and rock slopes of coastal structures. Journal of Waterway, Port, Coastal and Ocean Engineering, 118(5), 534-550.

VAN DE WALle, B., 2003. Wave Run-up on Rubble Mound Breakwaters, Gent: Ghent University, Ph.D. thesis.

\section{SYBMOLS}

$\alpha \quad$ slope angle $\left[{ }^{\circ}\right]$

$D_{n} \quad$ nominal diameter $[\mathrm{m}]$

$\delta \quad$ variation coefficient [-]

$H_{m 0} \quad$ significant wave height (frequency domain) = $4 \sqrt{m_{0}}[\mathrm{~m}]$

$H_{s} \quad$ significant wave height (time domain) defined as the average of the one-third highest waves [m]

$L_{o m} \quad$ deep water wave length $=g T_{01}^{2} / 2 \pi[\mathrm{m}]$

MHWS Mean High Water Spring $[Z+\ldots \mathrm{m}]$

MLWS Mean Lower Water Spring $[Z+\ldots \mathrm{m}]$

$N \quad$ number of waves [-]

$\mathrm{Nr} \quad$ number of wave run-up events [-]

NW northwest

p variable [-]

$q \quad$ wave overtopping discharge $\left[\mathrm{m}^{3} / \mathrm{sm}\right]$

$R d \quad$ wave run-down $[\mathrm{m}]$

$R d_{x \%} \quad$ wave run-down underspent by $x \%$ of the waves [m]

$R u \quad$ wave run-up [m]

$R u_{x \%} \quad$ wave run-up exceeded by $x \%$ of the waves [m]

$\mathrm{RU} \quad$ run-up gauge

$s_{o m} \quad$ wave steepness $=H_{m 0} / L_{o m}[\mathrm{~s}]$

SP spiderweb system

SWL Still Water Level $[Z+\ldots \mathrm{m}]$

TAW Tweede Algemene Waterpassing (Second General Leveling)

$t_{\mathrm{HW}} \quad$ moment of high water [h]

$t_{\mathrm{HW}}-i$ the $i$ th hour before $t_{\mathrm{HW}}[\mathrm{h}]$

$t_{\mathrm{HW}}+i \quad$ the $i$ th hour after $t_{\mathrm{HW}}[\mathrm{h}]$

$T_{m} \quad$ mean wave period in time domain [s]

$T_{01} \quad$ mean wave period $\left(=m_{0} / m_{1}\right)$ in frequency domain [s]

$T_{m-1,0} \quad$ spectral period $\left(=m_{-1} / m_{0}\right)[\mathrm{s}]$

$T_{p} \quad$ peak wave period in frequency domain [s]

$x \quad$ exceedance probability [-]

$\xi_{\text {om }} \quad$ Iribarren number $\left(=\tan \alpha / \sqrt{s_{o m}}\right.$ ) based on $T_{01}$ [-]

$Z \quad Z$-level $(Z+0.00=$ TAW $-0.11=$ MLLWS + 0.08 ) 
Copyright of Journal of Coastal Research is the property of Alliance Communications Group and its content may not be copied or emailed to multiple sites or posted to a listserv without the copyright holder's express written permission. However, users may print, download, or email articles for individual use. 